\title{
TRANSPARÊNCIA, REFLEXÃO E VICISSITUDE ${ }^{l}$
}

\author{
Waldomiro J. Silva Filho* \\ waldomiro.silva@pq.cnpq.br
}

RESUMO Este artigo discute a noção de condição de transparência proposta por Richard Moran em Authority and Estrangement (2001) segundo o qual a pergunta de primeira pessoa no tempo presente acerca da própria crença ("Eu acredito que p?") é respondida em referência às mesmas razões que justificam uma resposta para a pergunta correspondente acerca do mundo (acerca de verdade de p). A transparência, neste sentido, é uma característica fundamental do autoconhecimento no contexto da experiência comum e entender essa ideia nos ajuda a compreender as noções que estão normalmente associadas ao autoconhecimento, como imediatidade (não precisamos recorrer à observação ou inferência), autoridade de primeira pessoa (tenho acesso às minhas atitudes de um modo diferente das outras pessoas) e a relação entre o autoconhecimento, a racionalidade e a saúde psicológica da pessoa. Meu objetivo é, partindo de uma apresentação da condição de transparência e de algumas objeções a essa noção, oferecer uma interpretação da noção de transparência que favoreça uma concepção modesta de autoconhecimento e racionalidade que integra reflexão e vicissitude.

1 Este artigo foi escrito durante meu estágio de pós-doutorado no Departamento de Filosofia da Harvard University (Cambridge, Mass., Estados Unidos) quando me beneficiei de uma bolsa da CAPES (proc. n. 1052/09-8) e desenvolve um dos pontos centrais do tema da minha pesquisa como Bolsista de Produtividade do CNPq (proc. n. 306190/2007-9). Agradeço ao Prof. Richard Moran por sua acolhida generosa e ao Departamento de Filosofia da UFBA por ter autorizado que eu me afastasse das minhas atividades docentes durante um ano. Sou especialmente grato a Plínio J. Smith e ao parecerista anônimo da Kriterion por seus comentários críticos e sugestões que me ajudaram a entender várias fragilidades e incorreções presentes na primeira versão. Temo, entretanto, que esta versão do artigo ainda não responda a todos os pontos levantados por Plínio Smith e pelo parecerista. Mas, por honestidade intelectual - e sempre que se mostre pertinente - indico em notas de pé-de-página aquelas passagens que preservam problemas apontadas por essas pessoas. Creio que isso poderá ajudar você, leitor, a formar sua própria opinião sobre esse artigo.

* Professor do Departamento de Filosofia da Universidade Federal da Bahia.

KRITERION, Belo Horizonte, nº 123, Jun./2011, p. 213-236. 
Palavras-chave Autoconhecimento, condição de transparência, racionalidade.

ABSTRACT This article discusses the notion of transparency condition proposed by Richard Moran in Authority and Estrangement (2001). According to this notion the question in the first-person present tense about our own belief ("Do I believe in $\mathrm{p}$ ?") is answered in reference with the same reasons that justify the answer to a corresponding question about the world (about the truth of p). Transparency, in this sense, is the fundamental characteristic of self-knowledge in the context of common experience. Understanding this idea helps us to understand the notions which are normally associated to selfknowledge, such as immediacy (we do not need to turn to observation or inference) first-person authority (I have different access to my attitudes than other people do) and the relationship between self-knowledge, rationality and psychic health of a person. Through the presentation of the transparency condition and some objections to this notion, I aim to offer an interpretation of the notion of transparency which favors a modest conception of selfknowledge and rationality.

Keywords Rationality, self-knowledge, transparency condition.

\section{Autoconhecimento e Transparência}

Um dos assuntos recorrentes no debate recente sobre autoconhecimento e racionalidade é a ideia de que algumas das nossas atitudes, como crenças e pensamentos, são transparentes porque podemos saber que temos tais atitudes simplesmente considerando a verdade da proposição envolvida na atitude. Essa ideia de transparência encontra-se numa passagem muito citada e discutida de Gareth Evans:

“... in making a self-ascription of belief, one's eyes are, so to speak, or occacionally literally, directed outward - upon the world. If someone asks me 'Do you think there is going to be a third war?', I must attend, in answering him, to precisely the same outward phenomena as I would attend to if I were answering the question 'Will there be a third world war?' I get myself in a position to answer the question whether I believe that $p$ by putting into operation whatever procedure I have for answering the question whether $p$." 2 
Parece que algumas atitudes são transparentes no seguinte sentido: para a posição do ponto de vista de primeira pessoa do presente, entender o sentido de ter crenças ("Eu acredito que $p$ ?") envolve uma referência às mesmas razões que poderiam ser requeridas para compreender de que trata essa crença (a verdade de $p$ ). Isso porque minha crença sobre $p$ é equivalente, para mim e em condições comuns, à minha crença na verdade de $p$. Se alguém me pergunta "Você acredita que a crise mundial afetará a economia do Brasil?", ao responder, eu não investigo um fenômeno que ocorre no espaço interno da minha mente, olhando para dentro, mas, ao contrário, dirijo minha atenção para as condições e fatos econômicos do Brasil e para as informações a que posso ter acesso nos jornais. Assim estarei tratando do mesmo fenômeno que trataria se respondesse à pergunta "A crise mundial afetará a economia do Brasil?" Para Evans, se estou numa posição para afirmar que p, estou ipso facto numa posição para afirmar que "Eu acredito que $p$ " 3 .

Para Evans, ademais, a característica principal do uso do pronome "eu" é precisamente a autoreferência, o que significaria dizer que pensamentos cujo sujeito é "eu" (“"I'-thoughts") são pensamentos nos quais o sujeito do pensamento e da ação ("Eu penso ou acredito que..."; "Eu intento que...") está pensando sobre si mesmo, ou seja, está pensando acerca do sujeito do pensamento e da ação: "It is true that I manifest self-conscious thought, like 'here'-thought, in action; but I manifest it, not in knowing which object to act upon, but in acting" [grifos meus] ${ }^{4}$. Nestes termos, o que caracterizaria a perspectiva do sujeito não é um conhecimento de si (no modelo epistêmico análogo ao conhecimento das coisas e de outras mentes), mas uma capacidade de realizar o ato de manifestar seus atos e intenções.

Richard Moran $^{5}$ considera que a transparência no sentido de Evans é uma característica fundamental do autoconhecimento ${ }^{6}$ no contexto da

3 Cf. Ibid., pp. 225-226.

4 Ibid., p. 207.

5 Moran, 2001, p. 64.

6 Para Plínio Smith (2010), os filósofos analíticos atuais confundem autoconsciência e autoconhecimento e isso tem levado a equívocos no tratamento do tema da imediatez e da autoridade de primeira pessoa - que, segundo ele, valeria somente para a autoconsciência, não para o autoconhecimento. Nas suas palavas, "[n]i siempre se presta suficiente atención a la relación entre la conciencia de sí y el conocimiento de sí, llegándose por veces a identificarlos o creer que la primera implica inmediatamente y de manera no problemática el segundo. En mi modo de entender, no solamente la conciencia de sí es distinta del conocimiento de sí, sino también que ella no lo implica necesariamente. Si esto es cierto, entonces se podría decir que la autoridad de la primera persona expresa solamente la conciencia de sí y que, aunque muchas veces lleva a un conocimiento de sí, no es garantía de ese auto-conocimiento. Es siempre preciso saber cuando podemos confiar en la conciencia de sí y, basándonos en ella, alcanzar un conocimiento de la persona" (Ibid., p. 1). Minha inclinação é concordar com o seu argumento - o que, de certo modo, afeta o desenvolvimento do meu próprio argumento neste presente artigo. De fato, muitos filósofos se referem a autoconhecimento e autoconsciência sem fazer quaisquer distinções ou sem se preocupar em 
experiência comum e entender essa ideia nos ajuda a compreender as noções que estão normalmente associadas ao autoconhecimento, como imediatez (não precisamos recorrer à observação ou inferência), autoridade de primeira pessoa (tenho acesso às minhas atitudes de um modo diferente das outras pessoas) e a relação entre o autoconhecimento, a racionalidade e a saúde psicológica da pessoa.

As frases "Vai chover" e "Creio que vai chover" são obviamente diferentes porque aquilo de que trata a segunda é um fato acerca do meu próprio estado mental e a primeira se refere a um fato acerca do clima (que chove não depende de mim nem de que eu acredite nisso). Porém, para Moran, do ponto de vista da vida psicológica, normalmente quando uma pessoa está numa posição em que se questiona acerca das próprias atitudes e pergunta a si mesmo "Eu acredito que $p$ ?", sua resposta será formulada nos mesmos termos como a resposta à pergunta " $p$ é verdadeira?" . Esse modo de responder à pergunta sobre as próprias atitudes é completamente diferente do modo de responder à pergunta "S (outra pessoa) acredita que $p$ ?".

Considerando isso, Moran propõe aquilo que chama de Condição de Transparência (TC do inglês Transparency Condition $)^{8}$ e que poderia ser apresentado do seguinte modo:

(TC) A pergunta de primeira pessoa no tempo presente acerca da própria crença ("Eu acredito que $p$ ?") é respondida em consideração às mesmas razões que justificam uma resposta para a pergunta correspondente acerca do mundo (acerca de verdade de $p$ ).

Seguindo intuições que estão presentes em Evans, Moran apresenta uma imagem do autoconhecimento não como um tipo de "conhecimento" no sentido epistêmico do termo, tal como vem sendo amplamente discutido na tradição analítica, principalmente na querela compatibilismo e incompatibilismo entre

estabelecer precisamente os contornos conceituais dessas duas noções, como é o caso de Moran. Eu acredito que muitas vezes, entre alguns filósofos, a diferença entre uma abordagem cognitivo-epistêmica (conhecer os conteúdos da própria mente) ou perceptiva (dar-se conta dos próprios estados mentais) não ocupa um lugar crucial porque a questão central é oferecer uma perspectiva mais geral sobre aquilo que Lucy O’Brien chama de "how we relate to ourselves as subjects” (O'Brien, 2007, p. viii). Dizer isso, porém, não é uma resposta que evita a crítica de Smith. Plínio Smith está correto, no meu entendimento, em apontar que há uma confusão conceitual que nos dá a (falsa) impressão de que há um problema filosófico legítimo, a saber, a possibilidade do ceticismo acerca da própria mente. Devemos esclarecer essa confusão e, talvez, dissolver o problema. Mas, mesmo assim, eu preservo aqui esse uso confuso de autoconhecimento e autoconsciência, assumindo o seu ônus, pois decidir por esclarecer esses usos exigiria um esforço maior do que eu seria capaz de realizar no momento. Espero, em tempo oportuno, tratar detidamente desse tema e examinar melhor o argumento de Smith.

7 Ibid., p. 60.

8 Ibid., p. 62. 
anti-individualismo ou externismo e autoconhecimento ${ }^{9}$. Ao contrário, o autoconhecimento, para Moran, envolveria, em primeiro lugar, a habilidade que temos de expressar ou manifestar (avow) meu estado mental e não apenas a capacidade que tenho de atribuir estes estados a mim mesmo, tal como faço quando atribuo estados mentais a outras pessoas. Quando digo "Eu acredito que $p$ ", estou manifestando minha crença em $p$; de modo distinto, quando digo "S acredita que $p$ ", estou atribuindo a $\mathrm{S}$ um certo estado mental sem me comprometer com a verdade de $p$. Esse compromisso com a crença - e que envolve elementos psicológicos, morais e emocionais - seria um traço decisivo do conhecimento de si.

\section{Os Limites da Transparência}

Comentadores e críticos sugerem que existem certos limites e dificuldades na concepção de transparência exposta na noção de Condição de Transparência (TC $)^{10}$. Nesta seção, organizo essas críticas nas seguintes sub-seções: (II.1) a TC compreenderia uma concepção forte e racionalista de razão, pois estabelece que um indivíduo é um agente racional se somente se é um indivíduo capaz de refletir sobre suas próprias razões; (II.2) a TC, ao apoiar-se nas noções de transparente-em-relação-ao-mundo e transparência-como-compromisso, não explicaria a segurança especial dos avowals - o que enfraquece sua concepção de autoconhecimento; (II.3a) a TC exigiria que a pessoa tenha que julgar as próprias atitudes para conhecê-las e, assim, não consegue explicar a "imediatez do autoconhecimento" e; (II.3b) existem atitudes (que atribuímos a nós mesmos) que podem ser comumente conhecidas, mas que não são transparentes e, consequentemente a imediatez, a autoridade e a racionalidade, como traços do autoconhecimento, podem não ser justificadas pela TC.

$\mathrm{Na}$ minha opinião, estas críticas acertadamente estabelecem um vínculo entre a noção de $\mathrm{TC}$ e a) a racionalidade exigida ao agente, b) a natureza específica dos enunciados de primeira pessoa no presente e c) o traço de imediatez que deve ser característico do autoconhecimento. Porém, de acordo com o modo como entendo essa discussão, sou levado a concluir que estas

9 Sobre essa polêmica há uma vasta bibliografia. Como este não é o tema central deste artigo, remeto ao livro Mente, Linguagem e Mundo (Silva Filho, 2010) que reúne ensaios que debatem o modo como o autoconhecimento se tornou um problema filosófico central na filosofia analítica contemporânea.

10 A publicação de Authority and Estrangement, onde Moran desenvolve a noção de Condição de Transparência, desencadeou um importante debate e em torno deste livro há uma farta literatura, mas que não irei discutir aqui. Destaco algumas referências: Carman, 2003; O’Brien, 2003; Shoemaker, 2003; Heal, 2004; Lear, 2004; Reginster, 2004; Wilson, 2004; Moya, 2006; Bagnoli, 2007; Way, 2007; Child, 2009; Reed, 2010. 
críticas pode ser evitadas porque elas não interpretam adequadamente os argumentos centrais de Moran, sobretudo i) em relação ao tipo de concepção de racionalidade que lhe interessa, ii) pelo fato de que os críticos aqui citados consideram a TC como um "método de esclarecimento de crenças" e iii) ao lugar que Moran atribue à transparência na vida psicológica das pessoas. $\mathrm{Na}$ seção III a seguir voltarei a discutir esses pontos, apresentando uma leitura favorável às posições de Moran para, em seguida, extrair minhas próprias conclusões acerca da noção de autoconhecimento.

\section{II.1. Transparência e razão}

Brie Gertler situa os argumentos de Moran e a noção de Condição de Transparência num quadro que ele chama de "Rationalist Theory of Selfknowledge" (RTSK) e que incluiria também as posições de Tyler Burge, Akeel Bilgrami e Sydney Shoemaker (este último como uma forma moderada de racionalismo) ${ }^{11}$. Uma RTSK, de um lado, parte de uma crítica às concepções epistêmicas de autoconhecimento que apelam a teorias do conhecimento direto (acquaintance theory) e do sentido interno (inner sense theory) e, do outro lado, estabelece que o traço caracteristicamente especial do autoconhecimento é o pensamento crítico-reflexivo. A suposição fundamental de uma RTSK é que cada um de nós está numa posição única para avaliar e reconsiderar nossas próprias atitudes - em relação às quais somos responsáveis. E essa capacidade crítica seria a dimensão normativa do autoconhecimento.

A perspectiva racionalista que encontraríamos tanto em Moran quanto em Burge, poderia, segundo Gertler, ser resumida em quatro princípios básicos: a) somos indivíduos racionais, capazes de formar atitudes através de atos deliberativos; b) o ato de formar atitudes é uma atividade normativa e somos responsáveis por conduzir nossas atitudes em conformidade com as normas racionais; c) não poderíamos assumir esta responsabilidade a menos que sejamos capazes de conhecer nossas próprias atitudes. Assim, o nosso estatuto de agentes racionais exige que sejamos capazes de conhecer nossas próprias atitudes e; d) a nossa racionalidade, assim concebida, é o que explica o traço distintivo do autoconhecimento, a saber, ser um autoconhecimento crítico das atitudes.

Para Gertler, em Moran, o que permite o traço característico do autoconhecimento é algo que poderia ser chamado de "método da

11 Gertler, 2010b. A Profa. Brie Gertler gentilmente me permitiu consultar o manuscrito do seu Self-knowledge que aparecerá pela editora Routledge (London) em 2011. Até onde sei, este é o primeiro grande esforço para produzir uma síntese crítica do debate recente em torno do tema do autoconhecimento. 
transparência" ("transparency method") ${ }^{12}$. Mesmo que Moran nunca tenha usado essa expressão, tal "método" nos tornaria conscientes de nossas crenças (e de outras atitudes) através da reflexão sobre nossas razões. Para ele, em Moran, podemos "usar este método" ("We can use this method") porque há a suposição fundamental de que nossas atitudes são compromissos apoiados por razões que os justificam. Nesse ponto, a transparência se limitaria exclusivamente àquelas atitudes às quais podemos associar justificações racionais, incluindo razões teóricas e práticas. Se eu sou um agente racional, eu posso conhecer minha atitude acerca de $p$ quais as justificações que disponho garantir a verdade de $p$; ao rever e considerar minhas justificações posso, posteriormente, expressar a minha atitude intencional acerca $p$.

Isso, porém, nos levaria a um traço caracteristicamente racionalista da transparência: refletindo sobre a verdade de $p$ podemos formar as atitudes intencionais acerca $p$, ou seja, refletir criticamente sobre $p$ geraria atitudes acerca de $p$. Isso significaria que assim eu não tenho um autoconhecimento antes de recorrer ao "método da transparência" - pois é através dele que, finalmente, posso formar minhas atitudes. Ao recorrer ao suposto "método da transparência", a pessoa se torna não somente um agente racional, mas um racionalista, num sentido bastante forte, pois fica proibido de ter atitudes não-razoáveis.

\section{II.2. A segurança especial dos avowals}

O conceito de avowals (manifestação, expressão) é central para a noção de Condição de Transparência ${ }^{13}$. Porém, para Dorit Bar-On, dois elementos centrais da TC, a ideia de transparente-em-relação-ao-mundo (a concepção de transparência em Evans) e a ideia de transparência-como-compromisso (a ideia de transparência como uma forma de compromisso moral com a verdade de $p$ ), não explicariam o status privilegiado do tipo básico de autoconhecimento que estaria associado aos avowals ${ }^{14}$. De um lado, porque transparente-em-relaçãoao-mundo não revelaria os traços semânticos e epistêmicos característicos dos avowals e, do outro lado, a transparência-como-compromisso estaria limitada às autoatribuições de atitudes (especialmente crenças) que envolvem atos deliberativos.

Para compreender as críticas de Bar-On à TC, é necessário esclarecer o escopo geral do seu próprio projeto filosófico: o seu neo-expressivismo 
pretende oferecer uma teoria geral que explique a segurança especial dos avowals ${ }^{15}$. Segundo suas palavras:

"My goal will be to identify and explain a kind of security - special, even if not absolute - that we seem to enjoy whenever we issue an avowals, with respect to the state we self-ascribe, as well as with respect to the intentional object we specify for it, or the propositional content we assign to it, if any." 16

Essa teoria conciliaria dois aspectos-um semântico e outro epistêmico-que em geral estão dissociados nas outras teorias dos avowals (como na concepção cartesiana, na concepção materialista, em Anscombe, em Shoemaker e Evans). Segundo a Epistemic Asymmetry, avowals são genuinamente diferentes de outras ocorrências semânticas que envolvem recurso a evidências ou acesso epistêmico; para a Semantic Continuity, avowals exibem continuidade de estrutura lógico-semântica e são intercambiáveis salva veritate (em contextos) com frases ordinárias e não problemáticas ${ }^{17}$. Bar-On pretende então explicar a segurança especial de certas formas de enunciados e pensamentos de primeira pessoa sem negar que esses enunciados e pensamentos preservam certos traços lógicos e semânticos que podem comparecer em outras formas de enunciados e pensamentos, como, por exemplo, aquilo que outras pessoas podem dizer sobre mim ou o que meus relatos de memória podem dizer acerca de $\mathrm{mim}^{18}$.

Bar-On formula uma crítica que se dirige igualmente a Moran e Evans. Ela reconhece que a ideia de transparente-em-relação-ao-mundo, como aparece em Gareth Evans e é reelaborado em Richard Moran, oferece um bom argumento contra a concepção de introspecção e de espaço interno; entrementes, essa ideia não se aplica a todos os avowals nem exclusivamente a

15 Cf. Ibid., p. 141. Um comentário crítico sobre o neo-expressivismo encontra-se em Alexandre N. Machado, 2010, pp. 163-180.

16 Bar-On, 2004, p. 6.

17 Ibid., pp. 9-10.

18 Bar-On (Ibid., pp. 20 e 144) estabelece uma série de requisitos que a sua teoria conseguiria atender e que as outras teorias dos avowals não atendem. Sua teoria deve: a) explicar o que torna avowals protegidos de avaliações epistêmicas (como solicitações por razões, justificação da sua verdade, correções etc.); b) deveria explicar porque a segurança dos avowals não tem paralelos com outras formas de imputações de estados mentais (como, por exemplo, em terceira pessoa) e com imputações não-mentais em primeira pessoa. Em particular, deve explicar porque há nos avowals uma forte presunção de verdade; c) explicar o caráter inegociável desta forma de segurança - o fato de que é "intransferível" e "inalienável"; d) aplicarse tanto avowals intencionais quanto a avowals não-intencionais e nos permitir separar avowals de outras imputações em virtude da sua segurança; e) garantir a continuidade semânticas e a continuidade da estrutura lógica entre avowals e outras imputações; f) evitar que os avowals sejam retratados como absolutamente infalíveis e incorrigíveis; g) evitar apelar à ontologia dualista cartesiana; h) permitir a possibilidade de que avowals representem uma forma de autoconhecimento privilegiado e; i) prover uma visão não-deflacionista de autoconhecimento. 
avowals ${ }^{19}$. Neste ponto, Evans permaneceria comprometido com um "Acesso Epistêmico" já que avowals seriam baseados ou justificados em autoavaliações que a pessoa faz acerca de suas crenças e pensamentos em relação a algo no mundo externo ${ }^{20}$. Como uma forma de "Acesso Epistêmico", a ideia de transparente-em-relação-ao-mundo preservaria a exigência de que devemos possuir algum tipo de conhecimento prévio de nossas próprias mentes.

Grosso modo, assim como Gertler, Bar-On também encontra na noção de TC alguma semelhança com um "método da transparência". Para ela, este "método" seria epistemicamente indireto, pois quando a pessoa fala do que ocorre na sua mente ele precisa consultar o mundo ao seu redor. Esse, por assim dizer, "método" se aplicaria a uma limitada variedade de avowals, sobretudo àqueles casos onde somos perguntados explicitamente sobre se realmente acreditamos ou pensamos que $p$ (onde $p$ é uma proposição acerca de algo no mundo externo). Porém, se considerarmos outros avowals, como, por exemplo, "Eu realmente quero uma xícara de chá agora", "Eu estou muito preocupado com meu pai" ou, dito repentinamente, "Estou querendo saber qual é a hora", encontraremos casos onde não são lançadas questões que poderiam ser respondidas olhando diretamente para algo no mundo externo ${ }^{21}$. Se me pergunto, nesses casos, o que quero ou o que me preocupa, não preciso olhar o mundo lá fora.

Um outro problema seria que "avowals fenomênicos" (avowals que atribuem a presença de um estado sem conteúdo intencional, como, por exemplo, "Estou com sede") não parecem ser bons candidatos à aplicação do "método de transparência"; apenas avowals com conteúdo intencional, como crenças, responderiam a tal "método".

Para Bar-On, o "método da transparência" não explicaria corretamente a natureza dos avowals porque pode ser aplicado igualmente a não-avowals, como auto-relatos de percepção ("Eu estou vendo uma árvore") e auto-relatos de memória e, consequentemente não caracterizam um traço específico dos avowals. Na sua opinião, a concepção de transparência em Moran não promete mais do que a de Evans. De maneira genérica, suas críticas se concentram no fato de que algumas atribuições de estados mentais poderiam ser transparentesem-relação-ao-mundo, porém não partilhariam da segurança especial dos avowals, como é o caso, por exemplo, dos relatos de estados perceptivos ("Eu 
vejo uma árvore" ou "Eu ouço um som alto") ${ }^{22}$. Essas atribuições claramente atendem ao TC (embora Moran não tenha tratado diretamente desse tópico). Outro caso são as atribuições não-teóricas (no sentido apresentado por Moran $^{23}$ ) de estados mentais a outras pessoas: frequentemente, quando atribuímos crenças e outras atitudes aos outros, nosso olhar está dirigido ao mundo e não aos estados mentais internos da outras pessoa.

Outro aspecto é que a ideia de transparência-como-compromisso se aplicaria apenas a crenças e outros estados "motivados" ou "sensíveis a julgamentos" e não a todos os avowals. Isso quer dizer que o domínio da transparência seria restrito às autoimputações de atitudes cuja existência está sujeita à deliberação racional. Mesmo que a noção de transparência-comocompromisso possa caracterizar uma classe de autoimputações que é, ao mesmo tempo, distintivamente de primeira pessoa e genuinamente diferente de outras imputações, isto não fornece uma base sólida para que seja respeitada tanto a Assimetria Epistêmica quanto a Continuidade Semântica.

Além disso, a ideia de sujeito racional em Moran não ofereceria uma boa saída da perspectiva epistêmica: seguindo Kant e Sartre, Moran pensa autoridade especial dos avowals como resultado do exercício de uma autoridade racional de um sujeito racional que tem a capacidade reflexiva, autonomia e liberdade.

Dessarte, Moran não explicaria o status privilegiado do autoconhecimento básico que ordinariamente é associado aos avowals.

"Moran's view accommodates the kind of privileged self-knowledge we can have of what we shall believe, or desire, or intend, as we transparently deliberate, qua rational or practical agents, on the reasons for our beliefs, desires, and intentions. To the extent that this is the only kind of privileged self-knowledge he would make room for, his view of ordinary self-knowledge would seem deflationary (...). '24

Moran não teria explicado a natureza dos avowals (tanto intencionais quando não-intencionais) e das características do privilégio de primeira pessoa o que, consequentemente, comprometeria severamente sua compreensão do autoconhecimento. 


\section{II.3a. Acreditar e julgar}

Quassim Cassam critica o modo como Moran concebe a ideia de imediatez - ou seja, que o conhecimento de nossas próprias crenças e outras atitudes é usualmente imediato, não baseado em observação, evidência ou inferência ${ }^{25}$. Moran cometera aquilo que poderíamos chamar de "erro categorial", pois os exemplos de conhecimento imediato de nossas próprias crenças que ele considera são, na verdade, exemplos de conhecimento imediato de nossos julgamentos:

“...the point is that while consideration of the reasons in favour P might lead one to judge that $P$, judging that $P$ is not the same as believing that $P$ and does not ensure that one believes that $P$. This need not prevent one from knowing that one believes that $P$ on the basis of one's knowledge or awareness that one judges that $P$, but the resulting knowledge of one's belief is not immediate." 26

Moran não teria estabelecido uma diferença nítida entre a ideia de que o conhecimento dos nossos próprios atos mentais (como é o caso de julgar que) é imediato e a ideia muito mais complexa de que o conhecimento que temos dos nossos próprios estados mentais (como é o caso de ter uma crença) é imediato. Para Cassam, julgar, refletir, avaliar, concluir que $p$ (que são atos mentais) não é o mesmo que acreditar que $p$. Mesmo que, muitas vezes, julgar ou concluir que $p$ possa contribuir para a formação da crença que $p$, esta não é uma relação necessária já que o estado de acreditar não é causado necessariamente por avaliações, julgamentos e conclusões. Se, por acaso, julgar ou concluir que $p$ fosse equivalente a acreditar que $p$, do mesmo modo, conhecer que estou julgando ou concluindo que $p$ seria equivalente a conhecer que estou acreditando que $p$. Porém, segundo Cassam, é possível que alguém julgue que $p$, mas não acredite que $p$. É claro que pode ocorrer o caso em que um indivíduo pense que seu julgamento de que $p$ determina suas crenças, mas esse seria um sujeito excessivamente racionalista que teria a obrigação de examinar todas e cada uma das suas crenças, mesmo as mais elementares ("estou aqui neste momento"), para concluir que as tem. Moran esperaria, então, que a pessoa recorresse à reflexão para estabelecer suas razões e justificar sua crença.

Se entendermos que o conhecimento imediato deve ser um conhecimento não inferencial (e também um conhecimento não-observacional), em dois sentidos a TC não explicaria a imediatez do autoconhecimento: do ponto de vista 
epistêmico e do ponto de vista estritamente psicológico. Meu conhecimento de que $p$ é epistemicamente imediato se somente se minha justificação para acreditar que $p$ é não-inferencial; assim, também, meu conhecimento de que $p$ é psicologicamente imediato se somente se para chegar a esse estado de acreditar que $p$ eu não necessite recorrer a raciocínios e inferências acerca de $p$ ou de outras proposições.

Para Cassam, essa distinção entre imediatez epistêmica e imediatez psicológica nos leva a duas questões: a) quando venho a conhecer que eu acredito que $p$ seguindo o procedimento da transparência, o meu conhecimento é epistemicamente imediato? b) quando venho a conhecer que eu acredito que $p$ seguindo o procedimento da transparência, o meu conhecimento é psicologicamente imediato? Cassam argumenta, porém, que segundo a TC a resposta para as duas perguntas é não. Se aceitamos a TC quando venho a conhecer que eu acredito que $p$ seguindo o procedimento da transparência, $o$ meu conhecimento, ao menos em parte, exige a justificação de julgamentos, avaliações, raciocínios e inferências. Ora, o conhecimento inferencial não é conhecimento epistemica e psicologicamente imediato. A transparência, tal como Moran a concebe na sua TC, não tem como assegurar a imediatez (seja epistêmica ou psicológica) do autoconhecimento ${ }^{27}$.

\section{II.3b. Autoconhecimento sem transparência}

Um outro problema é que pode haver autoconhecimento sem transparência. Como salienta Jonanthan Way, "(...) there are rational attitudes - which can be recognized as such by their agents - which are just as resistant to transparency, and yet which can uncontroversially be the objects of ordinary self-knowledge" ${ }^{28}$. Ora, nem sempre os indivíduos têm as atitudes que julgam que são as atitudes que têm. É possível que alguém queira beber mais um copo de vinho, sabendo muito bem que esta não é a coisa certa a fazer já que terá de dirigir de volta para sua casa. Esses casos, quando a formação da atitude contraria o julgamento (a partir da reflexão sobre as atitudes), podem nos levar a colocar em dúvida a exigência da transparência como requisito fundamental do autoconhecimento 


\section{Reflexão e Vicissitude}

Esta seção está organizada em torno de três itens: (III.1) é fundamental para a definição de pessoa tanto supor que nossas vidas psicológicas são governadas ou explicadas pelas estruturas normativas dos conceitos de racionalidade e responsabilidade quanto supor que uma pessoa pode ou tem a capacidade de perguntar pelas razões da sua crença (isto servirá, do mesmo modo, para confrontar as teses de Gertler do hiper-racionalismo e de que haveria uma proto-crença anterior à intenção e, do mesmo modo, a crítica de Cassam sobre a diferença entre julgar e acreditar e, em outra direção, ajuda a esclarecer porque a TC não está a serviço de fundamentar a segurança especial dos avowals, como sugere Bar-On); (III.2) a TC não é um método para tornar crenças claras e distintas e o sentido de deliberação deve estar associado à ideia de "refazer a própria mente" (ao contrário do que fora sugerido por alguns comentadores e críticos, isto pode provar que Moran não concebe a TC como um "método", mas como uma condição modesta da nossa vida psicológica; isto ainda ajuda a refutar as críticas de que a TC envolve um racionalismo forte e estaria baseado numa confusão entre julgar e acreditar); (III.3) a TC demonstra a imediatez do autoconhecimento e autoridade especial da pessoa (ao contrário do que afirmam Bar-On e Cassam).

Nesta seção, por fim, sugiro que, do ponto de vista da experiência comum ${ }^{29}$ proposta por Moran em Authority and Estrangement, o sentido relevante de transparência envolve reflexão, posto que temos o direito legítimo de considerar, ponderar e avaliar as minhas próprias atitudes, e vicissitude, já que essas considerações que fazemos sobre nossas atitudes implicam precariedade, mudança e falibilidade.

\section{III.1. O direito legítimo de perguntar pelas razões da própria crença}

Para compreendermos corretamente o sentido da TC é importante ressaltar que Moran procura tratar o tema do autoconhecimento no cenário da vida comum e não recorre aos cenários dos experimentos mentais e da lógica modal (que, de certo modo, têm dominado o debate sobre autoconhecimento) ${ }^{30}$. Em que situação é relevante falar que temos (ou não temos) autoconhecimento? Ou ainda, por que uma pessoa perguntaria sobre as próprias crenças? Para muitos

29 A expressão ambígua "experiência comum" que estou usando aqui não tem um sentido técnico; referese apenas ao fato de que Moran trata seus temas filosóficos sem recorrer a cenários de experimentos mentais, a ambientes de lógica de mundos possíveis e teses de Semântica Filosófica - algo que se tornou hegemônico no debate atual sobre autoconhecimento.

30 Sobre isso, ver Santos, 2010 e Silva Filho, 2006. 
filósofos, um indivíduo é um agente racional não apenas porque lhe atribuímos crenças e pensamentos (e também outras atitudes), mas, sobretudo, porque acreditamos que ele tem um conhecimento de tais crenças e pensamentos e que ele pode refletir acerca dessas crenças e pensamentos. ("Refletir" aqui ainda é apenas uma noção vaga que pode significar avaliar, julgar, criticar, ponderar, comparar com outras atitudes passadas, antecipar consequências e assim por diante). As reflexões que um indivíduo faz acerca de suas próprias atitudes (mas também de suas emoções e sentimentos), frequentemente exercem um papel na condução da sua vida e nas mudanças dos seus estados mentais. Por isso, Moran estabelece uma distinção entre as situações onde a pessoa formula uma questão teórica e quando formula uma pergunta prática ou deliberativa acerca das próprias atitudes. O que ele chama de "theoretical question" acerca das próprias atitudes e sentimentos é aquela cuja resposta remete a algum conteúdo que a própria pessoa é ignorante, algo acerca do qual lhe falta um conhecimento; enquanto uma "practical or deliberative question" é aquela cuja resposta é uma deliberação, uma decisão que a pessoa tomará, afetando a condução da sua vida psicológica. Essa distinção $0^{31}$, segundo Moran, introduz uma nova dimensão para a questão da "substancialidade do autoconhecimento" 32; com essa distinção estaríamos numa posição que nos permite enxergar como a reflexão que os indivíduos fazem sobre seus próprios estados tem caráter dinâmico e joga um papel central nos seus atos intencionais e na transformação dos próprios pensamentos, crenças e sentimentos.

Neste ponto Gertler e Cassam acertam ao indicar a centralidade da refelxão na concepção de Moran acerca do autoconhecimento. Porém, essa reflexão deve ser interpretada num quadro de uma perspectiva modesta da racionaliade. Moran fala que procurou seguir uma estratégia que tentava assegurar um fundamento "tão minimalista quanto possível" acerca de como nossas vidas comuns são governadas ou explicadas pelas estruturas normativas dos conceitos de racionalidade, responsabilidade e ação ${ }^{33}$. Ou seja, ao contrário do que sugerira Gertler, Moran não reivindica uma concepção forte de razão e sujeito que justifique a capacidade do indivíduo de "considerar" suas atitudes. Ao contrário, a suposição de racionalidade é uma suposição básica e mínima para identificar o fenômeno do pensamento e da ação, assim como, de modo análogo, a suposição de que há algo como o "significado" é uma suposição 
básica e mínima para entender o fenômeno da fala ${ }^{34}$. Porém, assim como a suposição de significado não é uma garantia de que todos os atos de fala sejam bem sucedidos (e que as pessoas possam se comunicar com sucesso em todos os casos) ou que uma teoria filosófica semântica satisfaça plenamente a explicação global do fenômeno da fala (outras disciplinas, como linguística, fonoaudiologia, acústica, neurociência também podem iluminar, talvez até com mais eficiência, o fenômeno da fala), assim também a suposição filosófica de racionalidade e responsabilidade não garante que as pessoas ajam sempre de modo racional e responsável nem significa que tal teoria esgota o fenômeno da ação.

A suposição de racionalidade, portanto, não exige que o filósofo pense que a vida psicológica de uma pessoa é totalmente compreendida pelo conceito de racional ou de racionalidade para pensar que este é um requisito mínimo para qualquer investigação que procure entender todos os aspectos da vida psicológica das pessoas ${ }^{35}$. Num sentido holístico (no sentido Quine/ Davidson), a crença e de outras atitudes compreende estados mentais que são normativamente controlados e envolvem outros estados mentais que se suportam mutuamente. Os atos de uma pessoa normalmente são considerados ações (motivados por atitudes) e a pessoa é normalmente considerada um agente racional nesse quadro normativo.

De fato, como assinalam Lucy O'Brien ${ }^{36}$ e Pedro Stepanenko ${ }^{37}$, em Moran, a natureza especial do autoconhecimento está relacionada ao modo como uma pessoa tem consciência de si como agente racional ${ }^{38}$. Porém, a Condição de Transparência está sustentada naquilo que Moran chama de uma suposição modesta ("modest assumption") ou a mais modesta suposição ("the more modest assumption") ${ }^{39}$. A suposição modesta é a suposição de que as pessoas podem fazer e responder questões do tipo "O que eu penso sobre X?", ou seja, as pessoas têm a capacidade de fazer questões sobre o próprio estado

34 Cf. Ibid., p. 456.

35 Em outro lugar (Silva Filho e Dazzani, 2010) discuti o entendimento das próprias emoções.

36 Cf. O'Brien, 2003.

37 Cf. Stepanenko, 2008.

38 Neste ponto, desde a primeira versão deste artigo, sou traído pela confusão entre autoconsciência e autoconhecimento denunciada por Plínio Smith. O leitor atento perceberá que a partir deste parágrafo, nesta minha interpretação de Moran, estarei falando mais de autoconsciência do que que de autoconhecimento (sobretudo se tivermos em mente o debate acerca do compatibilismo e incompatibilismo entre externismo e conhecimento dos conteúdos próprios estados mentais). Como afirmei na nota número 6 acima, preservo esse uso confuso para deixar claro minha própria confusão conceitual. Uma confusão da qual ainda não pude me desvencilhar, pois saber que estou confuso, assim como saber que estou com dor de cabeça, não elimina a minha confusão ou a dor de cabeça - mas, sabendo disso, posso procurar um tratamento.

39 Cf. Moran, 2003, p. 413. 
mental. Essa suposição, porem, é fundamental para o conceito de pessoa como agente racional e marca uma diferença crucial entre a perspectiva de primeira e terceira pessoa. Ora, isto é fundamental para o conceito de agente racional porque a resposta a essa pergunta exerce influência sobre o modo como "refazemos nossas mentes". E é fundamental para estabelecer a diferença entre a primeira e terceira pessoa porque questões formuladas desta forma $(\mathrm{O}$ que eu penso sobre $\mathrm{X}$ ?), se expressa pela primeira pessoa, tem aspectos que não estão presentes quando expressa em relação a outra pessoa. Por exemplo, a questão "O que ele pensa sobre X?" envolve a atribuição teórica de um estado mental a outra pessoa; em relação a mim mesmo, como vimos na seção I deste artigo, quando me pergunto o que penso sobre $\mathrm{X}$, além do aspecto teórico, há principalmente o aspecto deliberativo ${ }^{40}$.

A imediatez, transparência e autoridade só serão postas em prática na medida em que as "razões" da pessoa realmente determinam o que suas crenças e outras atitudes são. O ponto é que os seres humanos, entre outras habilidades, têm a capacidade de agir de acordo com razões e de perguntar a si mesmo por essas razões. O aspecto do conceito de autoconhecimento que é relevante para os seus argumentos é que, considerada essa capacidade comumente outorgada às pessoas, a pergunta pelas próprias razões implica, de modo central, uma relação entre o conhecimento da própria atitude e as circunstâncias nas quais a pessoa realiza uma ação orientada pelos seus pensamentos e crenças e em relação às quais essa pessoa tem inalienável responsabilidade.

\section{III.2. Vivendo sem crenças claras e distintas}

É um erro considerar a TC como um "método" ou "procedimento" que teria o escopo de esclarecer ideias, crenças, pensamentos que, por alguma razão, estariam confusos, opacos, imprecisos na mente da pessoa. Imaginemos uma situação na qual uma pessoa que tem dúvidas sobre suas próprias crenças aplicasse esse "método da transparência" para saber qual é realmente a sua crença: ela examinaria, para isso, o mundo ao redor e depois, e somente depois, habilitar-se-ia a expressar sua crença; essa pessoa, ademais, teria uma capacidade crítico-filosófica muito sofisticada, nem sempre compartilhada pelas pessoas comuns, para proceder esse exame, investigando os conteúdos

40 Plínio Smith me fez ver que talvez isso dê razão a Cassam: afinal, Moran estaria falando da formação de crenças ou de conhecimento de crenças já formadas. Essa distinção é importante para delimitar o próprio argumento geral acerca da autoridade e imediatez. O parecerista anônimo da Kriterion também salientou esse ponto. Minha tendência é interpretar os argumentos de Moran como se dirigindo igualmente ao "conhecimento" ou à "investigação" das próprias crenças já formadas e ao processo de formação de novas crenças, aquelas que, pela reflexão, influenciarão a decisão. 
das suas atitudes - conteúdos esses que seriam formados, ao menos em parte, por eventos e objetos externos à mente - e aplicando complicados cálculos proposicionais. Obviamente que tal suposto "método" Evans-Moran de tornar crenças claras e distintas falharia em muitos episódios, pois responder a pergunta sobre a crença que $p$ olhando para o mundo ao redor (aos fenômenos empíricos) não é um candidato confiável e aplicável a todas as crenças em geral. Exemplos simples, como os apresentados por Bar- $\mathrm{On}^{41}$ e rapidamente comentados na seção II deste artigo, ilustram bem essa falha ${ }^{42}$.

Parece-me que a Condição de Transparência não fora concebida como tal método de tornar crenças claras e distintas e produzir autoconhecimento, mas como uma condição da experiência do dia-a-dia que pode interessar ao filósofo que pretende entender alguns dos traços da racionalidade humana. A autoatribuição de atitudes que satisfaz a TC são aquelas em que a resposta à pergunta sobre uma crença (Eu acredito que $p$ ?) tem um papel crucial na vida psíquica da pessoa exatamente porque essa pessoa pode "make one's mind up", "decidir-se", "refazer a própria crença".

Em Moran, o conceito de "avowal" é definido apenas como uma forma de caracterizar a posição enunciativa da primeira pessoa. Moran recorre a Wittgenstein para afirmar que há certas condições em que a pessoa concebe a si mesma como um sujeito psicológico de um modo radicalmente diferente das situações em que queremos entender outras pessoas. A função normal do uso do verbo "acreditar" no tempo presente pela primeira pessoa do singular é expressar ou manifestar uma perspectiva da pessoa sobre como as coisas estão no mundo - posto que frequentemente acreditar em algumas proposições é simplesmente acreditar que ela é verdadeira ${ }^{43}$. Mas não se pode criticar seriamente a TC por não oferecer uma teoria global da segurança especial das expressões de primeira pessoa no presente, pois este não é o seu objetivo. Seu objetivo, parece-me, é mais simples e desconcertante - a preocupação de Moran é moral e não epistêmica ${ }^{44}$. Ele não procura oferecer

41 Cf Bar-On, 2004, pp. 114-115.

42 O parecerista anônimo destaca que talvez fosse possível reconsiderar esse ponto. De um lado, a frase "eu estou preocupado com meu pai" não me parece claramente contrário a Evans/Moran já que parece decorrer de frases diretas do tipo "meu pai está doente" e "eu acredito que ele está doente", associado a uma atitude com direção de ajuste oposta, à qual a "transparência em relação ao mundo" não se aplica. Por outro lado, às outras frases e à dimensão avaliativa deste exemplo, a Condição de Transparência se aplica uma vez que se compreende como ela pode ser pertinente com a direção de ajuste adequada. Uma vez que eu decido tomar uma xícara de chá ou que quero saber a hora, não.

43 Cf. Moran, 2001, p. 74.

44 Discuto em outro artigo (Silva Filho, 2009) que o tratamento epistemológico da transparência do conteúdo tem obscurecido a noção de autoconhecimento e o lugar que essa noção ocupa na imagem que temos de pessoa e da ação humana. A contribuição de Moran seria deslocar o tema da Epistemologia e da Semântica Filosófica para a perspectiva da Psicologia Moral. 
um bom argumento ou uma explicação que esclareça como uma pessoa que se autoatribui uma atitude estaria numa posição particularmente segura, mas antes tenta entender, de um lado, como a autoatribuição é fundamental para a vida psíquica da pessoa porque essa atitude lhe importa ("are up to her/ him"). Por outro lado, ele considera o fato de que a pessoa tem uma autoridade não só porque suas crenças importam a ela, mas também no sentido de que essa pessoa, em certas circunstâncias, reflete sobre as razões dessa atitude no contexto de um ato deliberativo ${ }^{45}$.

\section{III.3. Transparência, imediatez e autoridade}

É fundamental, para o argumento de Moran, a discussão sobre o Paradoxo de Moore e a resposta de Wittgenstein na segunda parte das suas Investigações Filosóficas ${ }^{46}$. Uma resposta no espírito wittgensteineano considera que expressões como "Eu acredito que $p$ " não relatam ou descrevem um estado mental cognitivo, mas serve para apresentar ou expressar a aceitação da verdade da proposição em questão. Acerca disso, Wittgenstein escreveu: "Podemos desconfiar dos próprios sentidos, mas não da própria crença. Se houvesse um verbo significando 'crer falsamente', não teria uma primeira pessoa do presente do indicativo com significado. Em relação às minhas próprias crenças", continua, "não mantenho uma relação de conhecimento ou desconhecimento: Posso saber o que o outro pensa, e não o que eu penso. É correto dizer: 'Sei o que você pensa', e incorreto dizer: 'Sei o que eu penso"' 47 .

Em relação ao que as outras pessoas dizem ou dizem acreditar, posso confiar ou não confiar (que essa pessoa realmente acredita no que diz acreditar ou se o que diz acreditar é ou não verdadeiro). Com respeito às minhas próprias crenças, não há uma distância entre elas e o modo como os fatos fora de mim se apresentam para mim. O que Wittgenstein dissera acerca de não poder duvidar das próprias crenças não significa que eu confio mais nas minhas crenças do que confio nos meus sentidos, mas simplesmente que nessas

45 O parecerista anônimo comenta que, "de fato, uma preocupação central de Moran, anunciada desde o início do livro, é a colocar 'the more familiar epistemological questions in the context of wider self-other asymmetries' (Moran, 2001, p. 1), o que inclui discussões acerca de temas morais. Além disto, ele critica repetidamente uma solução puramente epistêmica, evidencial, da autoridade da primeira pessoa. Disto não se segue, no entanto, que ele não tenha uma preocupação epistêmica, ou pelo menos assim me parece. Em particular, se entendermos por uma preocupação epistêmica uma explicação de por que uma pessoa está justificada em fazer um determinado tipo de asserção (ou o que significa para uma pessoa estar justificada em fazer um determinado tipo de asserção), então parece-me que Moran tem também uma preocupação epistêmica (talvez se possa dizer que ele não tenha uma explicação epistêmica para este fato)".

46 Cf. Moran, 1997, p. 143-157; 2001, p. 66-99.

47 Wittgenstein, 2000, p. 222. 
situações não está em jogo confiança ou justificação epistêmica ${ }^{48}$. É claro que minhas crenças podem ser verdadeiras ou falsas (e é comum nos enganarmos), mas faria algum sentido eu confiar ou não confiar na minha crença ou duvidar que acredito? É claro que podemos, também, desconfiar das nossas próprias crenças ou estar insegura quanto a elas: essa situação não é incomum, pois alguém pode não confiar nas próprias crenças, mas isso significa que essa pessoa encontra-se numa situação normativamente irracional. (É claro que podemos imaginar uma situação na qual a pessoa tem uma baixa adesão a uma crença e que não se sinta segura em a admitir com firmeza ou até mesmo não se comprometa com tal crença. Isso, é claro, não pode ser classificado de irracional ${ }^{49}$.)

Um ponto que marca a radical diferença entre a primeira pessoa e a perspectiva de outra pessoa é que a relação entre a crença e o próprio fato de acreditar ou não acreditar não exige qualquer tipo de provas ou dados empíricos, já que expressar minha crença é expressar minha convicção sobre o que é o caso:

“... as I conceive of myself as a rational agent, my awareness of my belief is awareness of my commitment to its truth, a commitment to something that transcends any description of my psychological state. And the expression of this commitment lies in the fact that my reports on my belief are obliged to conform to the condition of transparency [grifo meu]: that I can report on my belief about X by considering (nothing but) X itself." 50

Autoconhecimento, nesse sentido, não é uma questão de ter acesso a uma informação sobre mim (informação que, por algum motivo, eu poderia não ter).

"When I avow a belief, I am not treating it as just an empirical psychological fact about me [grifo meu]; and to speak of a transcendental stance toward it is meant to register the fact that it is explicit in the avowal that it commits me to the facts beyond my psychological state; and as a commitment it is not something I am assailed by, but rather is mine to maintain or revoke. ${ }^{51}$

A pessoa, ao expressar sua crença, está se comprometendo com a sua verdade. $\mathrm{Na}$ vida comum, quando um indivíduo reflete deliberativamente acerca das suas crenças e pensamentos, não está fazendo uma investigação

48 Cf. Moran, 2001, p. 75.

49 Fui alertado sobre esse ponto por Plínio Smith.

50 Ibid., p. 84.

51 Ibid., p. 89. 
ou arrolando evidências e provas. Entrementes, mesmo sem as garantias epistêmicas, quando um indivíduo considera as suas próprias crenças ele pode (e frequentemente o faz) mudar sua mente (seus pensamentos, crenças e, claro, ações). Aqui há um tipo de autoridade de primeira pessoa indispensável à pessoa racional $\operatorname{comum}^{52}$; um tipo de autoridade que não se confunde com a autoridade epistêmica de um conhecimento claro e distinto acerca dos conteúdos completos da própria mente.

Quando a TC é violada, a ideia comum que temos da racionalidade das pessoas é profundamente abalada, pois parece que concebemos que um indivíduo é um agente racional não apenas porque lhe atribuímos crenças e pensamentos (e também outras atitudes), mas, sobretudo, porque supomos que ele pode refletir acerca dessas crenças e pensamentos e ser um sujeito dos seus atos mentais ${ }^{53}$. Sob muitos aspectos, ser um agente racional é ser capaz não só de ter atitudes, mas ser capaz de rever suas atitudes (mas também emoções e desejos) e formar novas atitudes:

“... part of it is to be a rational agent is to be able to subject one's attitudes to review in a way that makes a difference to what one's attitude is. One is an agent with respect to one's attitudes insofar as one orients oneself toward the question of one's beliefs by reflecting on what's true, or orients oneself toward the question of one's desires by reflecting on what's true worthwhile or diverting or satisfying. ",54

Como escrevera Stuart Hampshire, um sujeito racional é um "autor responsável por suas crenças" 55. Quando alguém diz "Eu acredito que X”, "Eu penso que X", "Eu desejo que X", essa crença, pensamento, desejo pertence a essa pessoa; essa pessoa é agente (autor) da atitude proposicional e ela tem uma "responsabilidade especial" que nenhuma outra pessoa tem. Essa crença, pensamento, desejo são expressão das suas relações com o mundo e com as outras pessoas e não uma "mera sucessão de representações (das quais, por alguma razão, ela é a única testemunha)" 56.

O que caracteriza nossa capacidade de autoconhecimento não é que os relatos de primeira pessoa são especial e cognitivamente garantidos e confiáveis, mas o fato de que esses relatos envolvem um modo específico

52 Não devemos esquecer que a consciência é um dos meios que dispomos para saber o que se passa em nós, se temos ou não tal crença. Mas esse não é o único meio e nem sempre é um meio seguro. $O$ depoimento das outras pessoas e incontáveis outros meios podem ser ainda mais confiáveis do que a consciência própria. Uma vez mais fui alertado sobre esse ponto por Plínio Smith.

53 lbid., p. 108.

54 Ibid., p 64.

55 Hampshire, 1965, p. 80.

56 Moran, 2001, p. 32. 
de consciência e que tal consciência tem consequências para o conjunto dos nossos pensamentos, desejos, crenças, para o que fazemos com nossas vidas e para a relação que mantemos com o mundo entorno. Se alguém é perguntado "O que você está fazendo?" e essa pessoa responde "Estou indo caminhar", esse enunciado não está baseado em alguma espécie de "indício interior"; ele expressa uma intenção para a qual essa pessoa (e ninguém mais) é responsável.

\section{Conclusão}

Algumas das críticas à noção de Condição de Transparência se concentram na acusação de que ela exige que a pessoa primeiro avalie e julgue suas atitudes e somente depois expresse suas intenções, como um sujeito hiper-racionalista que julga, reflete e pensa antes de acreditar. De fato, há uma expectativa de racionalidade atribuída às pessoas e a suposição de que somos capazes de refletir sobre nossas próprias atitudes. Mas, na verdade, o que a noção de TC estabelece é que, no contexto da vida prática comum, mesmo que muitas vezes nossas crenças nunca sejam objeto de reflexão ou que nunca sejamos instados a discriminar suas razões, o fato é que é possível para uma pessoa "chegar a uma conclusão", determinar suas crenças sobre algo se baseando simplesmente no seu acesso às razões para sustentar isso. A TC não afirma que todas as crenças são formadas através de deliberação ou raciocínio nem que nós precisamos aplicar ou recorrer a um "método" para tornar nossas crenças claras. A TC simplesmente supõe que esta é uma capacidade que as pessoas têm quando suas ações são regidas por razões.

As crenças e outras atitudes são transparentes neste sentido: a pessoa não precisa praticar a TC (fazer o ato de julgar) para que suas autoatribuições de atitudes sejam transparentes - refletir sobre as próprias razões é uma capacidade da pessoa; isso não é requisito ou exigência.

A autoridade da primeira pessoa e a imediatez do autoconhecimento são aspectos daquilo que é ser um sujeito de crenças, mas apenas na medida em que a pessoa tem o direito legitimo de supor que aquilo no que ela acredita sobre alguma coisa é determinada por aquilo que ela tem razões para acreditar. Entretanto, por mais que essa suposição seja indispensável para entender os indivíduos enquanto sujeitos que podem acreditar, conhecer, agir de acordo com razões, numa palavra, como pessoas, essa suposição se refere a uma capacidade humana que é parcial, frágil e imperfeita ${ }^{57}$. Esse talvez seja um 
dos motivos porque no decorrer das páginas de Authority and Estrangement Moran dedica uma atenção especial às vicissitudes e fraquezas da autoridade de primeira pessoa e como essas vicissitudes e fraquezas têm consequências para a racionalidade da pessoa.

Reflexão e vicissitude estão presentes no momento em que o indivíduo enquanto pessoa se encontra em situações em que a pergunta a si mesmo sobre sua crença torna-se inevitável para a condução da sua vida. Refletir não é mais do que expor as próprias atitudes sob um certo ângulo, considerando as próprias contingências, mudanças, precariedades e incertezas, enfim, considerar as próprias vicissitudes. Neste sentido, a ideia de racionalidade que interessa a Moran diz respeito ao exercício de uma particular autoridade sobre suas próprias crenças, pensamentos e intenções atuais. Mas essa é uma capacidade parcial já que a transparência não significa um entendimento completo dos conteúdos do pensamento; essa é uma transparência frágil, pois a psicopatologia da vida cotidiana está repleta de exemplos corriqueiros nos quais a transparência falha e não sabemos das nossas próprias razões; essa transparência é, ainda, imperfeita, já que não há garantias epistêmicas e metafísicas. Isso tudo serve para nos apresentar, ao mesmo tempo, a centralidade e fragilidade do autoconhecimento.

\section{Referências bibliográficas}

BAGNOLI, Carla (2007). "The Authority of Reflection", Theoria: An International Journal for Theory, History and Foundations of Science, Vol 22, No 1, pp. 43-52. BAR-ON. (2004). Speaking My Mind: Expression and Self-knowledge. Oxford: Oxford University Press.

CARMAN, Taylor (2003). "First Persons: On Richard Moran's Authority and Estrangement”, Inquiry, 46, pp. 395-408.

CASSAM, Quassim (2010a). "How We Know What We Think", Revue de Métaphysique et de Morale (no prelo).

CASSAM, Quassim (2010b). "Judging, Believing and Thinking", Philosophical Issues (no prelo).

CAVELL, Marcia (2006). Becoming a Subject: Reflections in Philosophy and Psychoanalysis. Oxford : Clarendon Press.

CHILD, William (2009). "Authority and Estrangement", Mind, vol. 118, n. 471, pp. 850-855.

EVANS, Gareth (1982). Varieties of Reference. Edited by John McDowell. Oxford, New York : Clarendon Press, Oxford University Press.

GERT LER, Brie (2010a). "Self-Knowledge and the Transparency of Belief", Hatzimoysis, Anthony (ed.). Self-Knowledge. Oxford : Oxford University Press (no prelo). 
GERT LER, Brie (2010b). "The Rationalist Theory of Self-Knowledge." SelfKnowledge. London : Routledge (no prelo).

HAMPSHIRE, S. (1965). Freedom of the Individual. New York: Harper \& Row.

HEAL, Jane (2004). "Moran's Authority and Etrangement", Philosophy and Phenomenological Research, vl. LXIX, n. 2, pp. 427-423.

LEAR, Jonathan (2004). "Avowals and Unfreedon", Philosophy and Phenomenological Research, vl. LXIX, n. 2, pp. 448-454.

MACHADO, Alexandre N. (2010). "Expressivismo, Verdade e Conhecimento", Silva Filho, Waldomiro J. (org.) Mente, Linguagem e Mundo. São Paulo: Alameda, pp. 163180

MORAN, R. (2001). Authority and Estrangement: An Essay on Self-Knowledge. Princeton, Oxford : Princeton University Press, 2001.

MORAN, Richard (2003). "Responses to O'Brien and Shoemaker", European Journal of Philosophy, 11:3, pp. 402-419.

MORAN, Richard (2004a). "Précis of Authority and Estrangement", Philosophy and Phenomenological Research, vl. LXIX, n. 2, pp. 423-426.

MORAN, Richard (2004b). "Replies to Heal, Reginster, Wilson, and Lear", Philosophy and Phenomenological Research, vl. LXIX, n. 2, pp. 455-472.

MORAN, Richard e Stone, Martin J. (2009). "Anscombe on Expression of Intention", Sandis, Constantine (ed.). New Essays on the Explantion of Action. New York: Palgrave Macmillan, pp. 132-168.

MOYA, Carlos J. (2006). "Moran on Self-knowledge, Agency, and Responsibility", Crítica, vl. 38, n. 114, pp. 3-20.

O'BRIEN, Lucy (2003). "Moran on Agency and Self-knowledge”, European Journal of Philosophy, 11:3, pp. 375-390.

REED, Baron (2010). "Self-Knowledge and Rationality", Philosophy and Phenomenological Research,

REGINSTER, Bernard (2004). "Self-knowledge, Responsibility, and Third Person", Philosophy and Phenomenological Research, vl. LXIX, n. 2, pp. 433-439.

SANTOS, C. S. dos (2010). "Exilados da Terra Gêmea: Os Experimentos Mentais e a Natureza da Intencionalidade", Silva Filho, Waldomiro J. (org.) Mente, Linguagem e Mundo. São Paulo: Alameda, pp. 281-291.

SHOEMAKER, Sydney (2003). "Moran on Self-knowledge", European Journal of Philosophy, 11:3, pp. 391-401.

SILVA FILHO, W. J. (2006). "O Autoconhecimento, o Narrador Onisciente e a Vida Comum", Philosophos, vol. 11, n. 2, pp. 287-303.

SILVA FILHO, (2009). "Três Considerações sobre Autoconhecimento e Transparência do Mental", Philosophos, Vol. 14, n. 2, pp. 163-181.

SILVA FILHO, W. J. e Dazzani, M. V. M. (2010). "Feelings, Imagination and SelfUnderstanding", Integrative Psychological and Behavioral Science, Vol. 44, No. (September), pp. 217-226.

SMITH, Plínio J. (2010). “Conciencia, Vanidad y Sorpresa” (inédito). 
STEPANENKO, Pedro (2008). “Autoconciencia y Agencia Epistémica em Kant y em Strawson", Unidad de la Conciencia y Objetividad: Ensayos sobre autoconciencia, subjetividad y escepticismo em Kant. México: Instituto de Investigaciones Filosóficas, pp. 41-68.

WAY, Jonanthan (2007). "Self-Knowledge and the Limits of Transparency", Analysis, n. 67.3, pp. 223-30.

WILSON, George M. (2004). "Comments on Authority and Estrangement", Philosophy and Phenomenological Research, vl. LXIX, n. 2, pp. 440-447.

WITGENSTEIN, L. (2000). Philosophical Investigations. Oxford, Cambridge: Basil Blackwell. 